OPEN ACCESS

Edited by:

Masakazu Toi,

Kyoto University, Japan

Reviewed by:

Stephen Grobmyer,

Cleveland Clinic Abu Dhabi,

United Arab Emirates

Simona Ruxandra Volovat,

Grigore T. Popa University of Medicine

and Pharmacy, Romania

Risal Djohan,

Cleveland Clinic, United States

*Correspondence:

Nicola Fusco

nicola.fusco@unimi.it

Specialty section:

This article was submitted to

Women's Cancer,

a section of the journal

Frontiers in Oncology

Received: 02 December 2019

Accepted: 10 March 2020

Published: 02 April 2020

Citation:

Invernizzi M, Lopez G, Michelotti A,

Venetis $K$, Sajjadi $E_{\text {, }}$

De Mattos-Arruda L, Ghidini M,

Runza L, de Sire A, Boldorini R and

Fusco N (2020) Integrating Biological

Advances Into the Clinical

Management of Breast Cancer

Related Lymphedema.

Front. Oncol. 10:422.

doi: $10.3389 /$ fonc. 2020.00422

\section{Integrating Biological Advances Into the Clinical Management of Breast Cancer Related Lymphedema}

\author{
Marco Invernizzi ${ }^{1}$, Gianluca Lopez ${ }^{2,3}$, Anna Michelotti ${ }^{3}$, Konstantinos Venetis ${ }^{4,5}$, \\ Elham Sajjadi ${ }^{3}$, Leticia De Mattos-Arruda ${ }^{6}$, Michele Ghidini ${ }^{7}$, Letterio Runza ${ }^{3}$, \\ Alessandro de Sire ${ }^{1,8}$, Renzo Boldorini ${ }^{9}$ and Nicola Fusco ${ }^{5,10 *}$ \\ 'Physical and Rehabilitative Medicine, Department of Health Sciences, University of Eastern Piedmont "A. Avogadro", \\ Novara, Italy, ${ }^{2}$ School of Pathology, University of Milan, Milan, Italy, ${ }^{3}$ Division of Pathology, Fondazione IRCCS Ca' Granda, \\ Ospedale Maggiore Policlinico, Milan, Italy, ${ }^{4}$ Ph.D. Program in Translational Medicine, University of Milan, Milan, Italy, \\ ${ }^{5}$ Divison of Pathology, IRCCS European Institute of Oncology (IEO), Milan, Italy, ${ }^{6}$ IrsiCaixa Foudation, Hospital Universitari \\ Germans Trias i Pujol, Badalona, Spain, 'Division of Medical Oncology, Fondazione IRCCS Ca' Granda, Ospedale Maggiore \\ Policlinico, Milan, Italy, ${ }^{8}$ Rehabilitation Unit, "Mons. L. Novarese" Hospital, Moncrivello, Italy, ${ }^{9}$ Pathology Unit, Department of \\ Health Sciences, Novara Medical School, Novara, Italy, ${ }^{10}$ Department of Oncology and Hemato-Oncology, University of \\ Milan, Milan, Italy
}

Breast cancer-related lymphedema (BCRL) occurs in a significant number of breast cancer survivors as a consequence of the axillary lymphatics' impairment after therapy (mainly axillary surgery and irradiation). Despite the recent achievements in the clinical management of these patients, BCRL is often diagnosed at its occurrence. In most cases, it remains a progressive and irreversible condition, with dramatic consequences in terms of quality of life and on sanitary costs. There are still no validated pre-surgical strategies to identify individuals that harbor an increased risk of BCRL. However, clinical, therapeutic, and tumor-specific traits are recurrent in these patients. Over the past few years, many studies have unraveled the complexity of the molecular and transcriptional events leading to the lymphatic system ontogenesis. Additionally, molecular insights are coming from the study of the germline alterations involved at variable levels in BCRL models. Regrettably, there is a substantial lack of predictive biomarkers for BCRL, given that our knowledge of its molecular milieu remains extremely puzzled. The purposes of this review were (i) to outline the biology underpinning the ontogenesis of the lymphatic system; (ii) to assess the current state of knowledge of the molecular alterations that can be involved in BCRL pathogenesis and progression; (iii) to discuss the present and shortterm future perspectives in biomarker-based patients' risk stratification; and (iv) to provide practical information that can be employed to improve the quality of life of these patients.

Keywords: breast cancer related lymphedema, pathobiology, genetics, breast cancer, survivorship, quality of life

\section{INTRODUCTION}

Breast cancer-related lymphedema (BCRL) is a particular form of secondary lymphedema occurring after axillary surgical procedures and/or irradiation in $14-54 \%$ of breast cancer survivors (1). Its clinical signs are related to an augmented volume of the upper limb due to tissue swelling and subsequent fibrosis (2). These include impaired function and strength, 
malaise, pain, comorbidities, and psychosocial frailty $(3,4)$. The diagnosis of BCRL is established by the measurement of the arm volume. Over the past decades, a wide variety of strategies have been proposed to identify and quantify alterations in the upper limb volume, including tape, perometry, bioimpedance, imaging (e.g., lymphography and magnetic resonance imaging), and augmented reality tools (5-9). BCRL prevention is centered on general healthcare suggestions, such as physical activity, body weight control, skincare, avoidance of infections (10). However, microsurgery-based primary prevention schemes, such as axillary reverse mapping and lymphatic-venous bypass, are showing promising results (11). For decades BCRL has been considered as an incurable condition but several therapeutic approaches are now available, both in the setting of physical therapy (e.g., complex decongestive therapy, manual lymph drainage, Qigong exercise, yoga, laser therapy, extracorporeal, shock wave therapy) and surgery (e.g., tissue excision, derivative microsurgery, microsurgical reconstruction, vascularized lymph node transfer, block of sympathetic innervation) (8, 1215). Regrettably, the pre-surgical identification of high-risk individuals is extremely challenging.

Despite these insights, the multifaceted biology of BCRL remains poorly understood due to the substantial lack of molecular data. Therefore, tailored prevention and treatment schemes are not routinely performed in these patients. In this review article, we seek to outline the biological and genetic changes in the lymphatic system development and impairment in breast cancer survivors, focusing on possible biomarkers for its risk assessment, diagnosis, prognostication, and treatment.

\section{PATHOPHYSIOLOGY}

\section{Ontogenesis of the Lymphatic System}

The lymphatic system is composed of a complex network of vessels and organs complementary to the cardiovascular system (16). It plays a crucial role in several biological events, including immune response and homeostasis of interstitial fluids, cells, molecules, and tissue debris (17, 18). At early stages of embryogenesis, the lymphatic vessels develop from the embryonic veins through the stepwise expression of numerous molecules, including prospero-related homeobox domain 1 (PROX1) and nuclear receptor subfamily 2, group F, member 2 (NR2F2) $(17,19)$. Interestingly, the silencing of these two genes in mice prevents lymphangiogenesis $(20,21)$. The lymphatic sac, which is lined by lymphatic endothelial cells (LECs), represents the earliest lymphatic structure (22). The LECs express lymphatic-specific proteins, such as vascular endothelial growth factor $\mathrm{C}$ (VEGFC). The absence of this molecule in animal models results in diffuse and lethal tissue swelling (23). The separation of the lymphatic system from the blood vessels leads to the formation of the lymphatic plexus (24). This process is mediated by a signaling pathway in which podoplanin (PDPN), expressed by the LECs, interacts with its receptor on platelets, promoting their aggregation (25). Subsequently, platelet microthrombi form a physical barrier that interrupts the communication between lymphatic and blood vessels $(26,27)$. Inactivating mutations in PDPN are related to defects in vascular system separation, and subsequent abnormal shunts $(24,27,28)$. The development of a contractile component (i.e., myoepithelial cells) coupled with that of a valve system allows for the unidirectional flow of the lymph fluid. This phase is characterized by the differential expression of PROX1, forkhead box protein C2 (FOXC2), GATA2, integrin $\alpha 9$ (ITGA9), and its ligand extra domain A fibronectin $(29,30)$. Their deficiency is associated with failure in valve formation and consequent lymphedema (31-33). The key molecular and transcriptional events in the lymphatic system ontogenesis are outlined in Figure 1.

\section{Fluid Drainage and Anatomic Considerations}

The lymph flow is determined by both intrinsic and extrinsic forces that promote lymph propulsion in the lymphatic conduct; intraluminal one-way valves minimize the backflow (34). Given the lack of a central pump for the lymph fluid, the flow is driven by rhythmic contractions of smooth muscle cells in the lymphatic vessels (35). Arterial pulsations, skeletal muscle compression, fluctuations of central venous pressure, gastrointestinal peristalsis, and respiration are also involved in this mechanism, representing the passive lymph pump. The entire interstitial drainage process is governed by the Starling equation (Figure 2). Three types of lymphatic channels are present, namely capillaries (also referred to as initial lymphatics), pre-collecting vessels, and collecting vessels (Figure 3). Capillaries are blind-ending vessels composed of a single layer of non-fenestrated LECs, with an incomplete basal lamina. These structures have specialized junctions and anchoring systems that act synergistically in promoting the passage of lymph from the interstitium to the lumen (36). Pre-collecting vessels are characterized by the alternation of propulsion segments (i.e., provided with muscular coat and intraluminal valves) and tracts with an absorbing architecture (i.e., irregularly-arranged of smooth muscle cells and discontinuous basal lamina) (37). These vessels converge into the collecting vessels, whose functional unit is represented by the lymphangion, defined as the segment between two valves (38). Lymphangions have zipper-like junctions between LECs, continuous basement membrane, well-represented muscular layer, and bi-leaflets one-way valves (39). It should be noted that the lymphatic network is asymmetric. Hence, the right lymphatic duct, which drains in the right subclavian vein, is present only in the right upper limb, the right side of the trunk, and the head and neck region (40), while all other territories are drained by the thoracic duct into the left subclavian vein (41).

\section{Understanding the Tissue Milieu: Inflammation and Matrix Response}

The soft tissue composition is a key factor in lymphatic homeostasis, as demonstrated by the increased risk of lymphedema related to fat accumulation $(8,42,43)$. Importantly, the lymphatic fluid stasis regulates the expression of genes with regulatory functions in adipogenesis, such as peroxisome proliferator-activated receptor gamma $(P P A R G)$ and CCAAT/enhancer-binding protein alpha (CEBPA) (44). Another key factor is represented by the adiponectin, a protein hormone involved fatty acid breakdown, that contributes to the signaling between adipose and immune cells and regulates the chronic inflammatory response (44). This protein can be overexpressed 


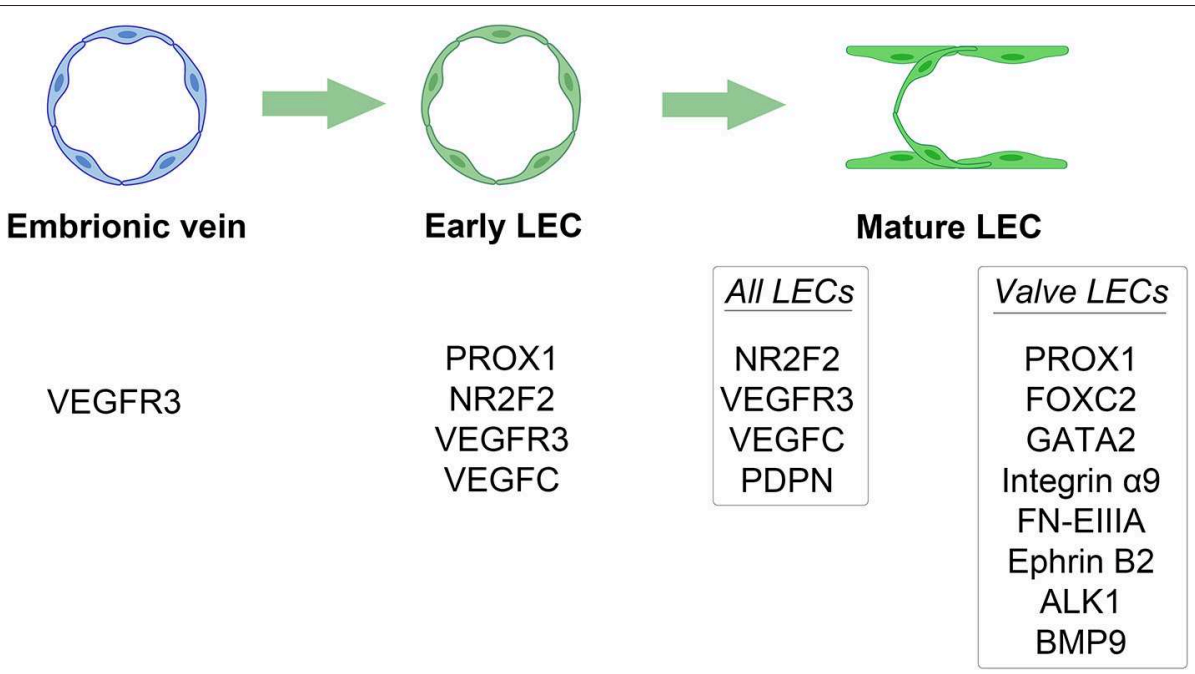

FIGURE 1 | Key molecular and transcriptional events in the lymphatic system ontogenesis. Different stages of lymphatic system development are outlined by their distinct stage-specific expression of different molecules. LEC, lymphatic endothelial cell.

in response to lymphatic fluid stasis, thus mediating the tolerance to proinflammatory stimuli in the case of obstruction $(44,45)$. Recently, adipose-derived stem cells co-cultured with human lymphatic endothelial cells have been shown to induce mRNA expression of lymphatic markers and proliferation/migration of lymphatic endothelial cells, without affecting tube formation (46). These data pave the way for possible engineering therapies to improve secondary lymphedema outcome.

Fibrosis and increased subcutaneous adipose tissue volume are the two main aspects of tissue remodeling which characterize late-stage BCRL (47). Therapeutic interventions designed to reduce their presence can increase the lymphatic function (48). In this respect, both cytokines and immune cells promote lymphangiogenesis, with a subsequent potential therapeutic role $(49,50)$. Interestingly, alternatively activated macrophages (M2) are often increased in lymphedema tissues, particularly in the setting of T helper 2 cell-mediated anti-inflammatory response in fibrotic phases (45). The macrophage infiltration in lymphedema decreases the overall inflammation and inhibits fibrosis (45). It has recently been proposed that a high capillary filtration coefficient coupled with increased plasma levels of VEGFC may constitute important biological traits of BCRL patients (51). Hence, a systemic increase in VEGFC promotes microvascular permeability, and an overload of the remaining lymphatic drainage capacity (52). On the other hand, the recovery of interstitial fluid drainage and the natural resolution of acute BCRL are not hindered by the administration of VEGF receptors blockers, suggesting that these processes are lymphangiogenesis independent. Taken together, the interstitial matrix plays a central role in the increase of lymph drainage (53).

\section{RISK STRATIFICATION: WHO IS LIKELY TO DEVELOP BCRL?}

Despite early detection can improve BCRL patients' outcome, the preventive options available to date are extremely limited
(54). The physical disruption of the arm lymphatics, such as in case of axillary lymph node dissection (ALND), is a well-established determinant of BCRL (55). Of note, both the number of lymph nodes removed and the number of metastatic lymph nodes are associated with an increased risk $(56,57)$. It has been hypothesized that this could be due to the higher dose of radiations that these patients receive in the axilla $(55,57)$. Hence, radiation-induced necrosis is likely to be involved BCRL pathogenesis (58). A higher prevalence of BCRL has also been observed in patients treated with anti-tumor systemic drugs, such as taxanes and trastuzumab, probably due to diminished lymphatic contractility (59-61). The correlation between body $\max$ index (BMI) $>25 \mathrm{~kg} / \mathrm{m}^{2}$, post-operative weight increase, dyslipidemia, and BCRL has been widely demonstrated (8). However, novel tumor-specific pathological features, such as peritumoral lymphovascular invasion and the extra-nodal extension of the metastatic deposits, have recently been proposed to improve BCRL risk stratification $(56,57)$. In general, there is a wide agreement that breast-conserving surgery is protective against long-term complications, including BCRL (62).

In addition to the classical mechanistic explanation, the study of the genetics underpinning BCRL has provided intriguing insights. Several germline alterations in genes involved at various levels in lymphangiogenesis have been documented in BCRL patients, suggesting a possible role for individual predisposition in the development of lymphedema following breast cancer therapy (Table 1). These genes include lymphocyte cytosolic protein 2 (LCP2), spleen associated tyrosine kinase $(S Y K)$, endothelial cell adhesion proteins (i.e., promoters, growth factors, and their receptors), interleukins, and K-channel genes (50, 63-72). Interestingly, these genes show recurrent somatic alterations in breast cancer, with a higher prevalence of gene copy-number alterations (CNAs) than somatic mutations (Figure 4). Despite these relevant observations, no tumorspecific recurrent molecular alterations have been identified in BCRL patients. 


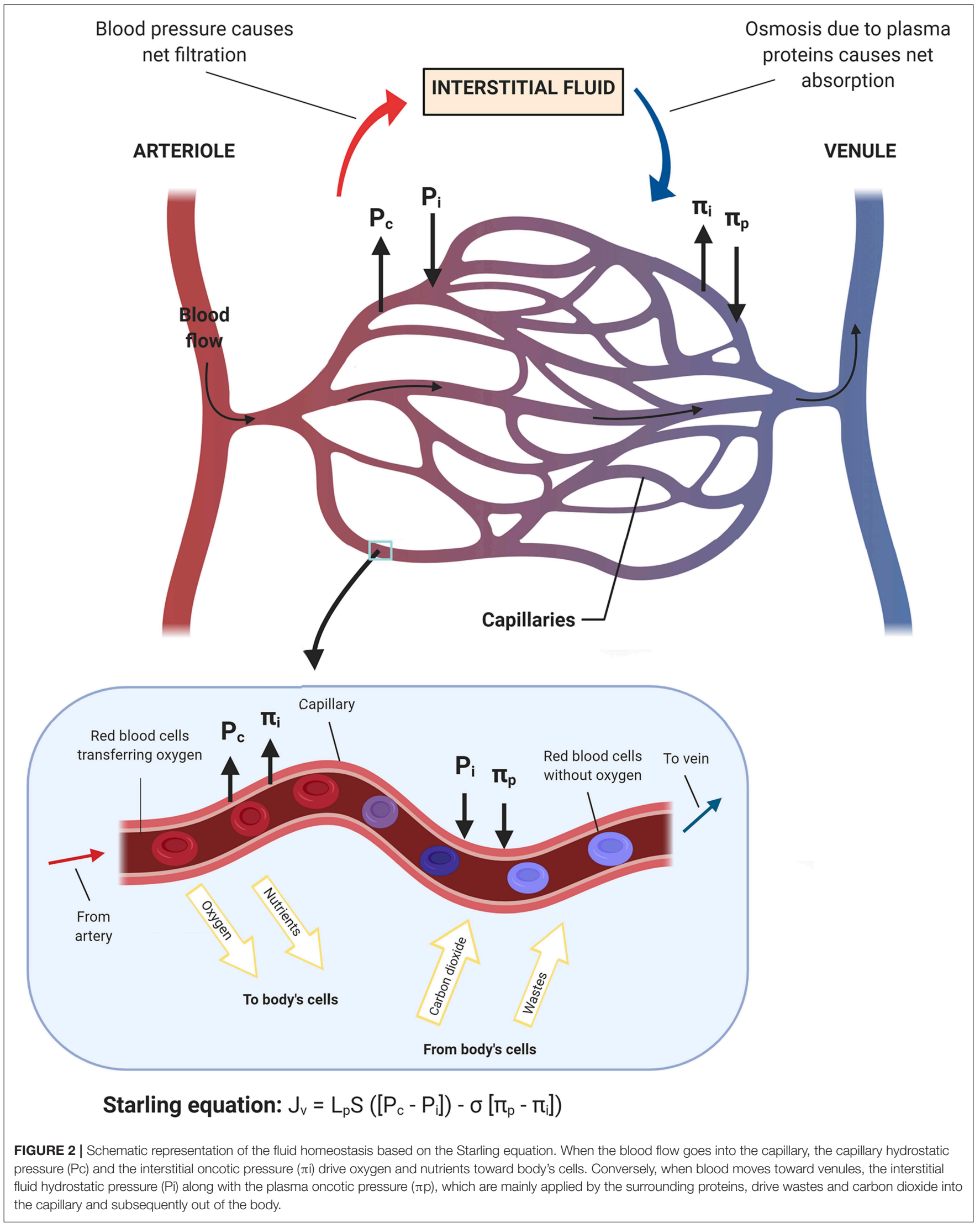




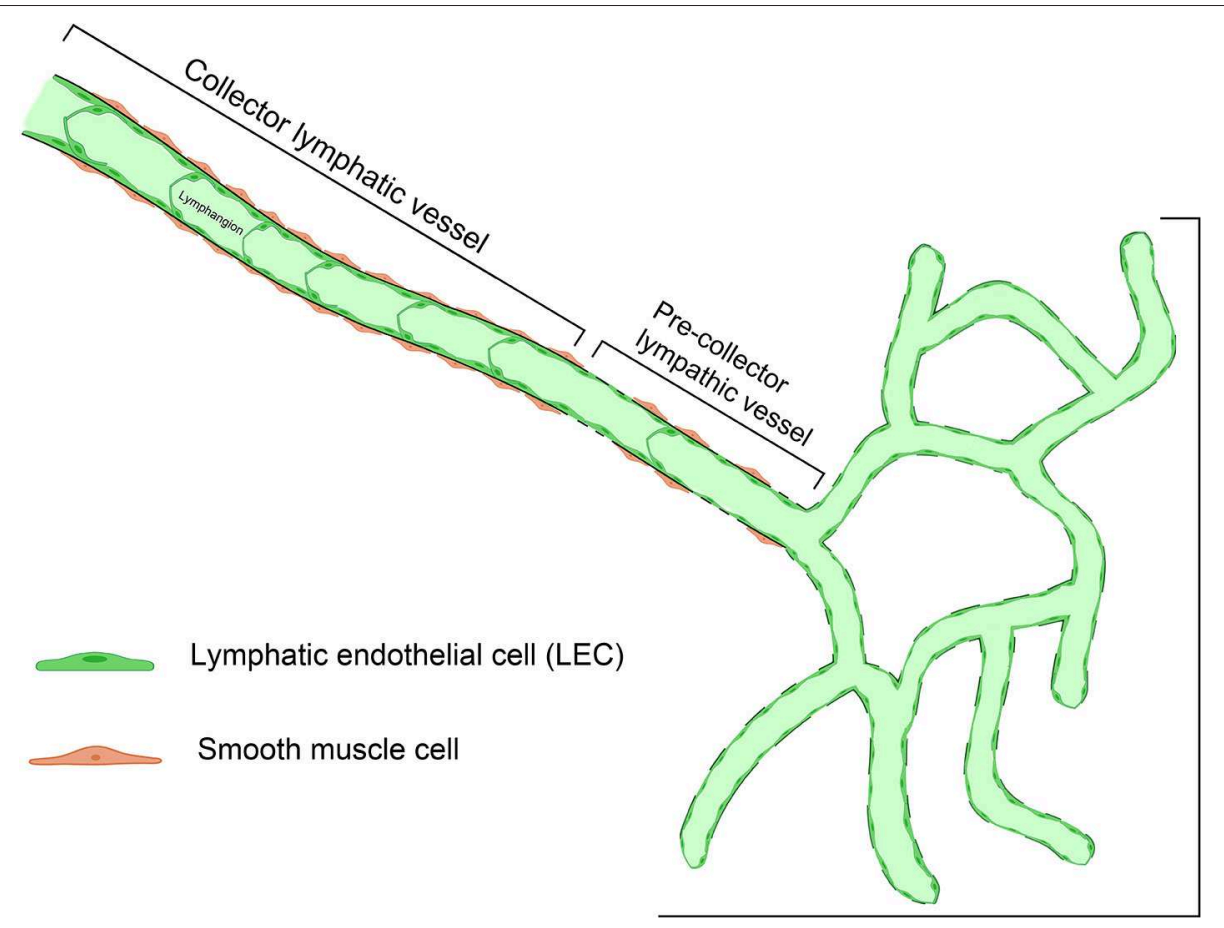

Lymphatic capillaries

FIGURE 3 | Representative structure of the different types of lymphatic vessels. Small, branching lymphatic capillaries lined by a single file of lymphatic endothelial cells (LEC) are connected to pre-collector lymphatic vessels, showing tracts with a discontinuous basal lamina. The collecting vessels, whose functional unit is the lymphangion, are larger in diameter and have a prevalent propulsion function.

\section{GENOMIC LANDSCAPE AND MOLECULAR HETEROGENEITY}

\section{Genetic Determinants and Putative Driver Alterations}

It has been suggested that BCRL susceptibility might have individual determinants, raising the possibility that therapyassociated lymphatic injuries might heighten a pre-existing deficit in the lymphatic function (73). Hence, among patients with BCRL, those with the involvement of the whole arm and hand showed an impairment of lymphatic function also in the contralateral unaffected arm (74). Following this circumstantial evidence, the detection of recurrent genetic traits is strategic to achieve the goal of precision medicine in BCRL.

\section{Lymphangiogenic and Angiogenic Genes}

In the last decade, the presence of alterations in genes related to lymphangiogenesis, lymphatic function, and permeability has been unraveled in BCRL. One of the most studied genes is $L C P 2$, which is involved in the immune response through the modulation of the T-cell signaling pathway (75). In addition, $L C P 2$ plays a central role in the lymphatic development, participating in the platelet-dependent mechanism of separation between blood and lymphatic vessels during embryogenesis $(26,76)$. Alterations in this gene are related to inherited lymphedema $(77,78)$. Copy-number alterations in LCP2 occur in $1.4 \%$ of breast cancer patients (Figure 4). They show a strong tendency toward co-occurrence with alterations in other genes known to be implicated in BCRL, such as interleukins (i.e., IL4, IL10, IL13) and neuropilin 2 (NRP2), as detailed in Table 2. NRP2 is a transmembrane glycoprotein expressed in blood and LECs, which is upregulated in the presence of ischemia and/or hypoxia (79-81). This protein is considered an important mediator of angiogenesis and lymphangiogenesis, acting as a co-receptor with VEGFC. This a molecule is encoded by two genes, namely VEGFC and Fms-related tyrosine kinase 4 (FLT4) (82-84). Somatic alterations in NRP2, FLT4, and $V E G F C$ have a strong tendency of co-occurrence in breast cancer (Table 2) and may predispose to secondary lymphedema $(68,69,73)$. Vascular cell adhesion protein 1 (VCAM1) is an adhesion molecule that promotes lymphocyte trans-endothelial migration in cytokine activated endothelium $(85,86)$. This adhesion molecule fosters tissue inflammation and contributes to lymphedema progression. CNAs in VCAM1 occur in $\sim 1 \%$ of breast cancer patients (Figure 4 ) and they are simultaneously present together with somatic alterations in other genes implicated in BCRL pathogenesis (Table 2). These include interleukins, nuclear kappa factor-beta 2 (NFKB2), $V E G F R / K D R$, as well as the hepatocyte growth factor (HGF) and its receptor MET. Six HGF/MET mutations in the sites of interaction and binding domain, respectively, were identified in secondary lymphedema, suggesting that altering this pathway can 
TABLE 1 | Genes that have been related to BCRL predisposition.

\begin{tabular}{|c|c|c|}
\hline Genes & Gene family & Function \\
\hline LCP2 & $\begin{array}{l}\text { Signal-transducing adaptor } \\
\text { protein }\end{array}$ & T-cell activation. \\
\hline SYK & Spleen tyrosine kinase & $\begin{array}{l}\text { Adaptive immune receptor signaling; } \\
\text { Cell proliferation, differentiation, and phagocytosis; } \\
\text { Separation of newly formed lymphatic vessels from the blood vasculature. }\end{array}$ \\
\hline VCAM1 & Cell adhesion promoters & Vascular endothelial cell adhesion and signal transduction. \\
\hline $\begin{array}{l}\text { HGF, HGFR/MET, VEGFC, FLT4, } \\
\text { VEGFR2/KDR, NRP2 }\end{array}$ & Growth factors and receptors & $\begin{array}{l}\text { Mitogenesis and morphogenesis; } \\
\text { Embryonic development; } \\
\text { Myocardial development; } \\
\text { Epithelial-mesenchymal transition; } \\
\text { Liver regeneration. } \\
\text { Cardiovascular development; } \\
\text { Angiogenesis; } \\
\text { Lymphangiogenesis; } \\
\text { Endothelial cell growth; } \\
\text { Permeability of blood vessels. }\end{array}$ \\
\hline NFKB2, RORC, FOXC2 & Transcription factor-coding & $\begin{array}{l}\text { Inflammation and immune response } \\
\text { Lymphoid organogenesis (in mice). } \\
\text { Valves development. }\end{array}$ \\
\hline GJC2, GJA4 & Connexins & $\begin{array}{l}\text { Arteriogenesis; } \\
\text { Oocyte survival; } \\
\text { Oligodendrocyte development. }\end{array}$ \\
\hline IL1A, IL4, IL6, IL10, IL13 & Interleukins & $\begin{array}{l}\text { Apoptosis and cell proliferation; } \\
\text { Immunoregulation and inflammation; } \\
\text { Expressed also in endothelial cells. }\end{array}$ \\
\hline KCNA1, KCNJ3, KCNJ6, KCNK3 & K channel proteins & $\begin{array}{l}\text { Electrochemical gradient across cell membranes; } \\
\text { In the lymphatic system facilitate lymph flow. }\end{array}$ \\
\hline
\end{tabular}

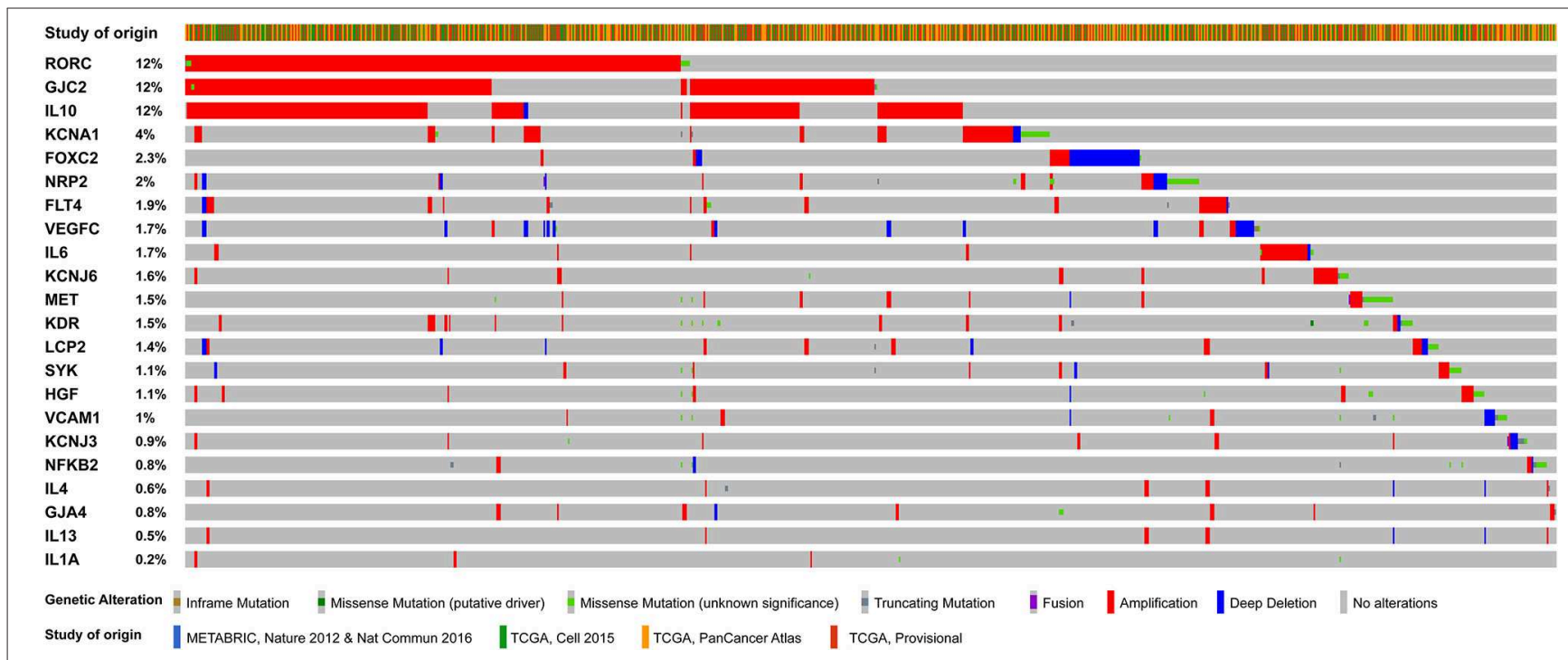

FIGURE 4 | Oncoprint visualization of the somatic molecular alterations in breast cancers ( $n=3,394$ samples) involving 22 genes with reported germline alterations in BCRL patients. Each column represents a sample, each row represents a gene, as reported on the left. The genes were sorted by alterations frequency (percentage on the left). Types of alterations and study of origin (publicly available at cBioportal.com) are color-coded on the basis of the legend on the bottom.

increase individual risk of developing lymphedema after breast surgery and thus providing a new potential therapeutic target (66). Another important gene in BCRL is represented by RARrelated orphan receptor gamma $(R O R C)$, which is known to be implicated in lymphangiogenesis, lymph node organogenesis, immune response, and cancer (87). Regrettably, the specific functions of this transcription factor in humans remain poorly understood. Interestingly, both somatic missense mutations and 
TABLE 2 | Significant trends in co-occurrence between pairs within genes linked to BCRL in breast cancer public datasets available at cBioPortal.

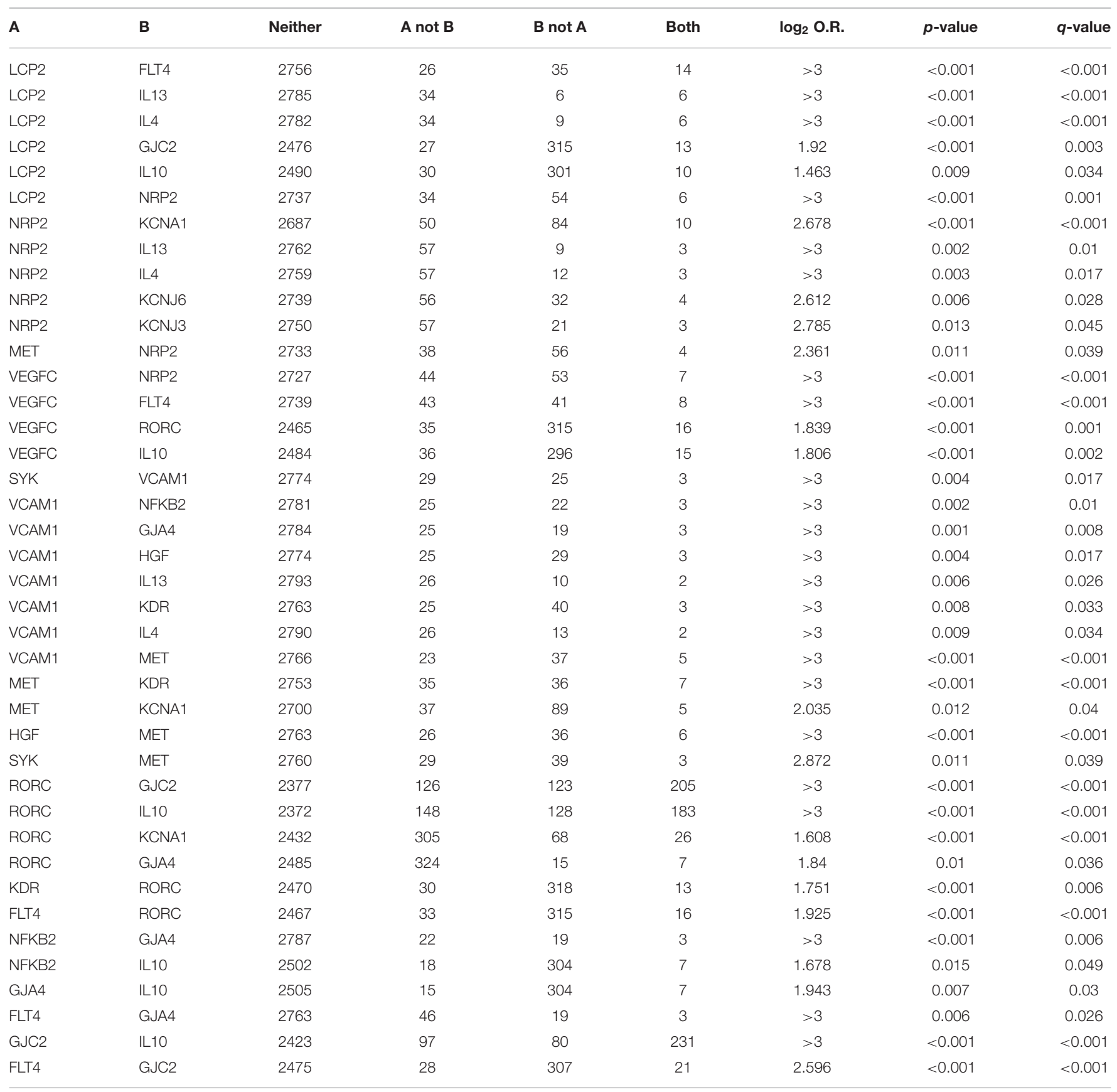

gene amplification in $R O R C$ are highly recurrent in breast cancers, being detected in up to $12 \%$ of patients (Figure 4). Alterations in this gene can be observed in patients that harbor alterations in other BCRL genes, such as FLT4, IL10, and VEGFR2/KDR (Table 2).

\section{Immunomodulation and Inflammatory Response}

Variations in pro-inflammatory (e.g., IL1, IL2, IL8, IL17, NFKB2) and anti-inflammatory (e.g., IL4, IL10, IL13) cytokines have been found in the circulating DNA of patients with BCRL (50). Among these, the single nucleotide polymorphisms (SNPs) significantly related to the development of unilateral arm swelling are those targeting NFKB2, IL10, and IL4. In particular, NFKB2 is a transcription factor involved in a multitude of biological processes, including (but not limited to) angiogenesis, cell proliferation, inflammation, tumorigenesis, and tumor progression (88). Alterations in this gene are relatively rare $(\sim 0.8 \%)$ in breast cancers and display the strong propensity toward co-occurrence with those targeting IL10, that are highly recurrent (12\%), as shown in Figure 4 and Table 2. IL10 is an anti-inflammatory cytokine that acts downregulating the expression of Th1 cytokines, MHC class II antigen-presenting 
molecules, and costimulatory molecules on macrophages (48). In particular, IL10 influences active transcription factor binding sites that are involved in lymphangiogenesis. Most importantly, this interleukin induces immunosuppression and tumor escape from immune surveillance, particularly in breast cancers lacking the expression of the estrogen receptor (89). Alterations in IL4 have also been detected in the circulating DNA of BCRL patients. This pleiotropic cytokine is produced by CD4+ T-cells and it has an important role in B-cell immune response modulation (48). This pathway is thought to be involved in alterations observed in lymphedematous tissues, such as fibrosis, adipose deposition, and lymphatic dysfunction $(48,90)$. Interestingly, it has been recently observed that cyclooxygenase $(\mathrm{COX}) 2$ and its product prostaglandin (PG)E2 are overexpressed in breast cancer stroma, having a possible role in lymphangiogenesis and metastatic spread s through lymphatics (91). Specifically, PGE2 activates the EP4 receptor in cancer cells and macrophages, promoting local VEGF-C/D overexpression, and LECs proliferation (91). All this information opens new avenues in BCRL risk stratification, providing that further prospective clinical studies will be designed to investigate whether NFKB2, IL10, IL4, and EP4 can be employed as circulating biomarkers for pre-surgical risk assessment.

\section{Transmembrane Diffusion and Inter-cellular Communication}

Connexins are a family of specialized transmembrane proteins that form the gap junctions between cells (70). They are crucial for both blood and lymphatic vessel homeostasis (70). Many authors have suggested that connexins may be implicated in the initial development of the lymphatic system, particularly in the formation of the lymphatic valves and $\operatorname{sac}(92,93)$. Mutations in genes encoding the connexins 47 and 37, namely gap junction protein gamma 2 (GJC2) and gap junction protein alpha 4 (GJA4), have been linked to both primary and secondary lymphedema $(67,72,94)$. Intriguingly, GJC2 CNAs are highly recurrent in breast cancer, being present in $12 \%$ of cases in the cBioPortal, as depicted in Figure 4. Furthermore, CNAs in GJC2 and GJA4 are significantly present together with somatic alterations in other BCRL genes, such as RORC, IL10, and FLT4 (Table 2). So far, these gap junction proteins represent promising biomarkers in both breast cancer and BCRL prognostication.

\section{Membrane Action Potential and Smooth Cell Contraction}

Several potassium channel genes were found to be the target of SNPs in the setting of secondary lymphedema. These genes include potassium voltage-gated channel subfamilies A member 1 (KCNA1), J member 3 (KCNJ3), 2 (KCNJ6), and $\mathrm{K}$ member 3 (KCNK3) (71). In particular, KCNA1 is a transmembrane protein selective for potassium-positive ions; its functions are to shape the action potential and promote the return of the depolarized membrane to its resting state. KCJN3 and KCJN6 are inward rectifying channels that act in an opposite way to voltage gated-channels, supporting the flow of positively charged potassium ions into the cell and stabilizing the resting membrane of cells $(38,71)$. Finally, KCNK3 is another relevant tissue factor that contributes to the maintenance of the resting potential, giving rise to the background or outward leak potassiumpositive currents (38). Despite the great efforts that have been made to determine the influence of genetic predisposition in BCRL pathophysiology, these analyses have several limitations. Larger sample sizes could reveal additional associations between polymorphisms and BCRL.

\section{Biological Characteristics of the Primary Tumors}

The possible existence of molecular indicators evaluable in a pre-operative/operative setting remains one of the key topics surrounding BCRL. For this aim, a search on the public genomic database cBioPortal has been conducted to determine whether genetic alterations associated with both congenital and postsurgical lymphedema occurred also in breast cancer. A correlation between lymphedema candidate genes and mutations in the primary tumor could be useful as an indicator of patients' individual susceptibility, along with the well-known treatment-related risk factors. A query was submitted in order to search genetic alterations of literature driven genes in 2,509 breast cancer samples from METABRIC (Molecular Taxonomy of Breast Cancer International Consortium) project. Notably, in almost all cases genetic alterations found in candidate gene consist of gene amplification, while previous genetic studies individuated single nucleotide polymorphisms associated with BCRL. Most genes were altered in a small percentage of tumor samples, ranging from 0.1 to $2.5 \%$. However, three of them were amplified in at least one-fifth of the breast cancer cases. Specifically, the RORC gene was amplified in $20 \%$, GJC2 in $24 \%$ and IL10 in $25 \%$ of samples.

To date, the function of RORC's encoded protein in humans remains poorly understood. However, there are several lines of evidence to suggest that this gene may play a part in lymphoid organogenesis and thymopoiesis regulation (87). In addition, RORC protein plays a role in the expression of some clock genes and its expression has been linked to breast cancer survival outcomes (95). RORC overexpression seems to increase distant metastasis-free survival in breast cancer patients (96-98). However, given the lack of knowledge on its precise function and interactions in humans, it is not possible to speculate on the role of RORC in BCRL pathogenesis, preventing also any consideration of the correlation between its amplification and lymphedema occurrence. Connexins are widely expressed in the normal mammary glands, where gap junctions have distinct functions in development and homeostasis, such as modulation of cell proliferation and lactation (99). In advanced breast neoplasms, they are believed to increase the capacity of tumor cells to metastasize through enhancing their invasion and adhesion ability as well as by protecting tumor cells from hypoxia-induced death (100-102). Furthermore, some subtypes of connexins, namely $\mathrm{Cx} 26, \mathrm{Cx} 32$, and $\mathrm{Cx} 43$ are overexpressed in metastatic lymph nodes of ductal carcinomas $(103,104)$. These findings suggest that, in later stages, connexins facilitate the metastatic involvement of locoregional lymph nodes. However, further studies are required to support this hypothesis.

Immunoregulatory cytokines, such as IL10, are important actors in tumor microenvironment associated with breast cancer. Specifically, IL10 is a pleiotropic anti-inflammatory cytokine with 
a dual role in breast cancer, exhibiting both pro- and anti-tumor activities (105). Its intricate molecular pattern of interactions has not been fully elucidated yet, however, this regulatory molecule is thought to take part in tumor initiation and progression, promoting immunosuppression and tumor immune evasion. IL10 predominantly displays a tumor-inhibiting activity through the activation of NK cells, enhancement in surface expression of MHC antigen and promoting tumor infiltration by neutrophil and macrophages (106). In the opposite way, IL10 may also reduce immune response against cancer, mainly decreasing the antigen presentation capacity and modulating the production of several cytokines. Hence, higher levels of IL10 may increase tumor immune escape and this hypothesis is consistent with the observation of increased IL10 concentration in serum of breast cancer patients, particularly in case of metastatic disease (89). Hypothesizing that gene amplification leads to an increase in protein expression, IL10 immunosuppressive properties could the metastatic potential of breast cancer, increasing the risk of lymph node involvement, which represents a well-known predisposing factor for BCLR. These assumptions on the possible prognostic value of IL10 amplification for lymphedema risk prediction remain largely speculative. However, some studies found higher IL10 levels in metastatic lymph nodes and IL10 polymorphisms associated with increased expression in patients with lymph node-positive breast cancer $(107,108)$. Interestingly, high IL10 levels were also found in inflammatory breast cancer, a particularly aggressive and highly metastatic form of breast cancer, in which this cytokine correlates with the presence of lymphovascular invasion (109). This parameter has been recently associated with an increased risk of BCRL in patients with left side localization.

In summary, there is no specific evidence to date that genetic alterations in primary tumor play a direct role in BCRL pathogenesis. However, the correlation between somatic mutations and higher rates of nodal involvement could indirectly lead to more aggressive therapeutic schemes, including ALND and axillary radiation, and thus increasing the odds of developing post-surgical lymphedema.

\section{LYMPHANGIOGENESIS-RELATED MECHANISMS AS POTENTIALLY DRUGGABLE TARGETS}

All these novel data suggest that novel individualized therapeutic strategies can be realistically implemented. In particular, the crucial role of VEGF and the observation of BCRL improvement in patients treated with anti-VEGF monotherapy provided evidence for the possible role of anti-angiogenic drugs in lymphedema treatment (110). In particular, a pilot study was conducted in order to evaluate the efficacy and safety of bevacizumab, a monoclonal antibody directed against VEGF, in patients with lymphedema following breast cancer treatment (110). The working hypothesis was that VEGFinhibitors could significantly reduce interstitial fluid collection through the modulation of vascular permeability, resulting in an indirect improvement of lymphatic obstruction and drainage. Preliminary study results confirmed the hypothesis that Bevacizumab has a role in interstitial fluid pressure and extracellular fluid volume reduction (NCT00318513). However, many aspects limit its use in clinical practice for breast cancer patients. To date, Bevacizumab is no longer approved for breast cancer treatment and there is only partial evidence regarding the use of VEGF-inhibitors in subjects without active cancer. Lymph fluid collection represents the starting point of BCRL, which is worsened by chronic inflammatory tissue response to protein-rich fluid accumulation. The modulation of immune signal molecules, such as interleukins, could reduce inflammation and tissue reaction, preventing lymphedema chronicization. In this setting, a trial is ongoing to test the efficacy of peripheral intravenous injections of a combination of two monoclonal antibodies that neutralize the biologic activity of IL4 and IL13 (NCT02494206). Further clinical studies are needed to develop targeted therapies directed to improve lymphatic regeneration and function, together with the modulation of inflammatory pathways. An appropriate medical treatment combining physical and molecularly targeted drugs administered early on after surgery in high-risk individuals could become the key strategy to prevent lymphedema formation.

\section{CONCLUSIONS}

BCRL is a complex and underdiagnosed condition, with potentially devastating consequences on the quality of life of breast cancer survivors. Several genetic, anatomical, biological, and clinical factors might intervene in its development, supporting the hypothesis of a multifactorial etiopathogenesis. Impairment of the lymphatic system embryogenetic differentiation mechanisms, anatomical variations, alterations of the lymphatic pacemaking system, mechanisms of phasic contractions of the lymphatic vessel, and systemic inflammation might act synergistically. In addition, mutations in genes encoding inter-cellular communication have been linked to both primary and secondary lymphedema. There is no evidence that genetic alterations related to the different molecular subtypes of breast cancer could influence BCRL pathogenesis. On the other hand, medical, surgical, and radiation therapies are crucial factors in its development and progression. Further research is needed in order to clarify, according to a novel multidisciplinary approach, the strict correlation between clinical and biological aspects of BCRL. The identification of specific molecular targets, novel biomarkers, and validated risk stratification tools could prove significantly crucial, bringing us closer to achieving the goal of precision medicine for BCRL.

\section{AUTHOR CONTRIBUTIONS}

MI and NF: study concept and design. MI, RB, and NF: supervision. GL, AM, AS, and LR: manuscript writing (first draft). AM: bibliography. GL, KV, and ES: iconography. LD and MG: first draft revision. All authors: revision and approval of the final draft. 


\section{REFERENCES}

1. Vicini F, Shah C, Arthur D. The increasing role of lymphedema screening, diagnosis and management as part of evidence-based guidelines for breast cancer care. Breast J. (2016) 22:358-9. doi: 10.1111/tbj.12586

2. Cheville AL, McGarvey CL, Petrek JA, Russo SA, Thiadens SR, Taylor ME. The grading of lymphedema in oncology clinical trials. Semin Radiat Oncol. (2003) 13:214-25. doi: 10.1016/S1053-4296(03)00038-9

3. Boyages J, Kalfa S, Xu Y, Koelmeyer L, Mackie H, Viveros H, et al. Worse and worse off: the impact of lymphedema on work and career after breast cancer. Springerplus. (2016) 5:657. doi: 10.1186/s40064-016-2300-8

4. Sayegh HE, Asdourian MS, Swaroop MN, Brunelle CL, Skolny MN, Salama L, et al. Diagnostic methods, risk factors, prevention, and management of breast cancer-related lymphedema: past, present, and future directions. Curr Breast Cancer Rep. (2017) 9:111-21. doi: 10.1007/s12609-017-0237-8

5. Tewari N, Gill PG, Bochner MA, Kollias J. Comparison of volume displacement versus circumferential arm measurements for lymphoedema: implications for the SNAC trial. ANZ J Surg. (2008) 78:889-93. doi: $10.1111 / j .1445-2197.2008 .04686 . x$

6. Hidding JT, Viehoff PB, Beurskens CH, van Laarhoven HW, Nijhuis-van der Sanden MW, van der Wees PJ. Measurement properties of instruments for measuring of lymphedema: systematic review. Phys Ther. (2016) 96:1965-81. doi: 10.2522/ptj.20150412

7. Shah C, Vicini FA, Arthur D. Bioimpedance spectroscopy for breast cancer related lymphedema assessment: clinical practice guidelines. Breast J. (2016) 22:645-50. doi: $10.1111 /$ tbj. 12647

8. Michelotti A, Invernizzi M, Lopez G, Lorenzini D, Nesa F, De Sire A, et al. Tackling the diversity of breast cancer related lymphedema: perspectives on diagnosis, risk assessment, and clinical management. Breast. (2019) 44:1523. doi: $10.1016 /$ j.breast.2018.12.009

9. Invernizzi M, Runza L, De Sire A, Lippi L, Blundo C, Gambini D, et al. Integrating augmented reality tools in breast cancer related lymphedema prognostication and diagnosis. J Vis Exp. (2020). doi: 10.3791/60093

10. Asdourian MS, Skolny MN, Brunelle C, Seward CE, Salama L, Taghian AG. Precautions for breast cancer-related lymphoedema: risk from air travel, ipsilateral arm blood pressure measurements, skin puncture, extreme temperatures, and cellulitis. Lancet Oncol. (2016) 17:e392-405. doi: 10.1016/S1470-2045(16)30204-2

11. Boccardo F, Casabona F, De Cian F, DeCian F, Friedman D, Murelli F, et al. Lymphatic microsurgical preventing healing approach (LYMPHA) for primary surgical prevention of breast cancer-related lymphedema: over 4 years follow-up. Microsurgery. (2014) 34:421-4. doi: 10.1002/micr.22254

12. Ezzo J, Manheimer E, McNeely ML, Howell DM, Weiss R, Johansson KI, et al. Manual lymphatic drainage for lymphedema following breast cancer treatment. Cochrane Database Syst Rev. (2015) CD003475. doi: 10.1002/14651858.CD003475.pub2

13. Brorson H. Liposuction in Lymphedema Treatment. J Reconstr Microsurg. (2016) 32:56-65. doi: 10.1055/s-0035-1549158

14. Runowicz CD, Leach CR, Henry NL, Henry KS, Mackey HT, CowensAlvarado RL, et al. American Cancer Society/American Society of Clinical Oncology Breast Cancer survivorship care guideline. J Clin Oncol. (2016) 34:611-35. doi: 10.1200/JCO.2015.64.3809

15. Yamamoto T, Yamamoto N, Hayashi A, Koshima I. Supermicrosurgical deep lymphatic vessel-to-venous anastomosis for a breast cancer-related arm lymphedema with severe sclerosis of superficial lymphatic vessels. Microsurgery. (2017) 37:156-9. doi: 10.1002/micr.22382

16. Standring S. Gray's Anatomy, The Anatomical Basis of Clinical Practice. London:Elsevier (2015).

17. Nicenboim J, Malkinson G, Lupo T, Asaf L, Sela Y, Mayseless O, et al. Lymphatic vessels arise from specialized angioblasts within a venous niche. Nature. (2015) 522:56-61. doi: 10.1038/nature14425

18. Pagni F, Guerini-Rocco E, Schultheis AM, Grazia G, Rijavec E, Ghidini M, et al. Targeting immune-related biological processes in solid tumors: we do need biomarkers. Int J Mol Sci. (2019) 20:5452. doi: 10.3390/ijms20215452

19. Srinivasan RS, Escobedo N, Yang Y, Interiano A, Dillard ME, Finkelstein D, et al. The Prox1-Vegfr3 feedback loop maintains the identity and the number of lymphatic endothelial cell progenitors. Genes Dev. (2014) 28:2175-87. doi: $10.1101 /$ gad.216226.113
20. Wigle JT, Oliver G. Prox1 function is required for the development of the murine lymphatic system. Cell. (1999) 98:769-78.

21. Johnson NC, Dillard ME, Baluk P, McDonald DM, Harvey NL, Frase SL, et al. Lymphatic endothelial cell identity is reversible and its maintenance requires Prox1 activity. Genes Dev. (2008) 22:3282-91. doi: 10.1101/gad.1727208

22. Suzuki H, Watabe T, Kato M, Miyazawa K, Miyazono K. Roles of vascular endothelial growth factor receptor 3 signaling in differentiation of mouse embryonic stem cell-derived vascular progenitor cells into endothelial cells. Blood. (2005) 105:2372-9. doi: 10.1182/blood-2004-07-2547

23. Karkkainen MJ, Haiko P, Sainio K, Partanen J, Taipale J, Petrova TV, et al. Vascular endothelial growth factor $\mathrm{C}$ is required for sprouting of the first lymphatic vessels from embryonic veins. Nat Immunol. (2004) 5:74-80. doi: 10.1038/ni1013

24. Watson SP, Lowe K, Finney BA. Platelets in lymph vessel development and integrity. Adv Anat Embryol Cell Biol. (2014) 214:93-105. doi: 10.1007/978-3-7091-1646-3_8

25. Wiig H, Swartz MA. Interstitial fluid and lymph formation and transport: physiological regulation and roles in inflammation and cancer. Physiol Rev. (2012) 92:1005-60. doi: 10.1152/physrev.00037.2011

26. Bertozzi CC, Hess PR, Kahn ML. Platelets: covert regulators of lymphatic development. Arterioscler Thromb Vasc Biol. (2010) 30:2368-71. doi: 10.1161/ATVBAHA.110.217281

27. Uhrin P, Zaujec J, Breuss JM, Olcaydu D, Chrenek P, Stockinger H, et al. Novel function for blood platelets and podoplanin in developmental separation of blood and lymphatic circulation. Blood. (2010) 115:3997-4005. doi: 10.1182/blood-2009-04-216069

28. Hess PR, Rawnsley DR, Jakus Z, Yang Y, Sweet DT, Fu J, et al. Platelets mediate lymphovenous hemostasis to maintain blood-lymphatic separation throughout life. J Clin Invest. (2014) 124:273-84. doi: 10.1172/JCI70422

29. Bazigou E, Xie S, Chen C, Weston A, Miura N, Sorokin L, et al. Integrin-alpha9 is required for fibronectin matrix assembly during lymphatic valve morphogenesis. Dev Cell. (2009) 17:175-86. doi: 10.1016/j.devcel.2009.06.017

30. Koltowska K, Betterman KL, Harvey NL, Hogan BM. Getting out and about: the emergence and morphogenesis of the vertebrate lymphatic vasculature. Development. (2013) 140:1857-70. doi: 10.1242/dev.089565

31. Kriederman BM, Myloyde TL, Witte MH, Dagenais SL, Witte CL, Rennels M, et al. FOXC2 haploinsufficient mice are a model for human autosomal dominant lymphedema-distichiasis syndrome. Hum Mol Genet. (2003) 12:1179-85

32. Dagenais SL, Hartsough RL, Erickson RP, Witte MH, Butler MG, Glover TW. Foxc2 is expressed in developing lymphatic vessels and other tissues associated with lymphedema-distichiasis syndrome. Gene Expr Patterns. (2004) 4:611-9. doi: 10.1016/j.modgep.2004.07.004

33. Petrova TV, Karpanen T, Norrmén C, Mellor R, Tamakoshi T, Finegold $\mathrm{D}$, et al. Defective valves and abnormal mural cell recruitment underlie lymphatic vascular failure in lymphedema distichiasis. Nat Med. (2004) 10:974-81. doi: 10.1038/nm1094

34. Gashev AA. Physiologic aspects of lymphatic contractile function: current perspectives. Ann N Y Acad Sci. (2002) 979:178-87; discussion 188-196. doi: 10.1111/j.1749-6632.2002.tb04878.x

35. von der Weid PY, Zawieja DC. Lymphatic smooth muscle: the motor unit of lymph drainage. Int J Biochem Cell Biol. (2004) 36:1147-53. doi: 10.1016/j.biocel.2003.12.008

36. Baluk P, Fuxe J, Hashizume H, Romano T, Lashnits E, Butz S, et al. Functionally specialized junctions between endothelial cells of lymphatic vessels. J Exp Med. (2007) 204:2349-62. doi: 10.1084/jem. 20062596

37. Sacchi G, Weber E, Aglianò M, Raffaelli N, Comparini L. The structure of superficial lymphatics in the human thigh: precollectors. Anat Rec. (1997) 247:53-62.

38. Ohhashi T, Mizuno R, Ikomi F, Kawai Y. Current topics of physiology and pharmacology in the lymphatic system. Pharmacol Ther. (2005) 105:165-88. doi: 10.1016/j.pharmthera.2004.10.009

39. Arkill KP, Moger J, Winlove CP. The structure and mechanical properties of collecting lymphatic vessels: an investigation using multimodal nonlinear microscopy. J Anat. (2010) 216:547-55. doi: 10.1111/j.1469-7580.2010. 01215.x 
40. Smith ME, Riffat F, Jani P. The surgical anatomy and clinical relevance of the neglected right lymphatic duct: review. J Laryngol Otol. (2013) 127:128-33. doi: $10.1017 /$ S0022215112002939

41. Hematti H, Mehran RJ. Anatomy of the thoracic duct. Thorac Surg Clin. (2011). 21:229-38. doi: 10.1016/j.thorsurg.2011.01.002

42. Zampell JC, Aschen S, Weitman ES, Yan A, Elhadad S, De Brot M, et al. Regulation of adipogenesis by lymphatic fluid stasis: part I. Adipogenesis, fibrosis, and inflammation. Plast Reconstr Surg. (2012) 129:825-34. doi: 10.1097/PRS.0b013e3182450b2d

43. McDuff SGR, Mina AI, Brunelle CL, Salama L, Warren LEG, Abouegylah M, et al. Timing of lymphedema following treatment for breast cancer: when are patients most at-risk? Int J Radiat Oncol Biol Phys. (2018) 103:62-70. doi: 10.1016/j.ijrobp.2018.08.036

44. Aschen S, Zampell JC, Elhadad S, Weitman E, De Brot M, Mehrara BJ. Regulation of adipogenesis by lymphatic fluid stasis: part II. Expression of adipose differentiation genes. Plast Reconstr Surg. (2012) 129:838-47. doi: 10.1097/PRS.0b013e3182450b47

45. Ghanta S, Cuzzone DA, Torrisi JS, Albano NJ, Joseph WJ, Savetsky IL, et al. Regulation of inflammation and fibrosis by macrophages in lymphedema. Am J Physiol Heart Circ Physiol. (2015) 308:H1065-77. doi: 10.1152/ajpheart.00598.2014

46. Strassburg S, Torio-Padron N, Finkenzeller G, Frankenschmidt A, Stark GB. Adipose-derived stem cells support lymphangiogenic parameters in vitro. $J$ Cell Biochem. (2016) 117:2620-9. doi: 10.1002/jcb.25557

47. Coriddi M, Khansa I, Stephens J, Miller M, Boehmler J, Tiwari P. Analysis of factors contributing to severity of breast cancer-related lymphedema. Ann Plast Surg. (2015) 74:22-5. doi: 10.1097/SAP.0b013e31828d7285

48. Avraham T, Zampell JC, Yan A, Elhadad S, Weitman ES, Rockson SG, et al. Th2 differentiation is necessary for soft tissue fibrosis and lymphatic dysfunction resulting from lymphedema. FASEB J. (2013) 27:1114-26. doi: 10.1096/fj.12-222695

49. Choi I, Lee YS, Chung HK, Choi D, Ecoiffier T, Lee HN, et al. Interleukin-8 reduces post-surgical lymphedema formation by promoting lymphatic vessel regeneration. Angiogenesis. (2013) 16:29-44. doi: 10.1007/s10456-012-9297-6

50. Leung G, Baggott C, West C, Elboim C, Paul SM, Cooper BA, et al. Cytokine candidate genes predict the development of secondary lymphedema following breast cancer surgery. Lymphat Res Biol. (2014) 12:10-22. doi: $10.1089 / \mathrm{lrb} .2013 .0024$

51. Jensen MR, Simonsen L, Karlsmark T, Bülow J. Microvascular filtration is increased in the forearms of patients with breast cancer-related lymphedema. J Appl Physiol. (2013) 114:19-27. doi: 10.1152/japplphysiol.01116.2012

52. Jensen MR, Simonsen L, Karlsmark T, Lanng C, Bülow J. Higher vascular endothelial growth factor-C concentration in plasma is associated with increased forearm capillary filtration capacity in breast cancer-related lymphedema. Physiol Rep. (2015) 3:e12403. doi: 10.14814/phy2.12403

53. Mendez U, Brown EM, Ongstad EL, Slis JR, Goldman J. Functional recovery of fluid drainage precedes lymphangiogenesis in acute murine foreleg lymphedema. Am J Physiol Heart Circ Physiol. (2012) 302:H2250-6. doi: 10.1152/ajpheart.01159.2011

54. Kilbreath SL, Refshauge KM, Beith JM, Ward LC, Ung OA, Dylke ES, et al. Risk factors for lymphoedema in women with breast cancer: a large prospective cohort. Breast. (2016) 28:29-36. doi: 10.1016/j.breast.2016.04.011

55. Goldberg JI, Riedel ER, Morrow M, Van Zee KJ. Morbidity of sentinel node biopsy: relationship between number of excised lymph nodes and patient perceptions of lymphedema. Ann Surg Oncol. (2011) 18:2866-72. doi: 10.1245/s10434-011-1688-1

56. Vieira RA, da Costa AM, de Souza JL, Coelho RR, de Oliveira CZ, Sarri AJ, et al. Risk factors for arm lymphedema in a cohort of breast cancer patients followed up for 10 years. Breast Care. (2016) 11:45-50. doi: $10.1159 / 000442489$

57. Invernizzi M, Corti C, Lopez G, Michelotti A, Despini L, Gambini D, et al. Lymphovascular invasion and extranodal tumour extension are risk indicators of breast cancer related lymphoedema: an observational retrospective study with long-term follow-up. BMC Cancer. (2018) 18:935. doi: 10.1186/s12885-0184851-2
58. Shaitelman SF, Chiang YJ, Griffin KD, DeSnyder SM, Smith BD, Schaverien $\mathrm{MV}$, et al. Radiation therapy targets and the risk of breast cancer-related lymphedema: a systematic review and network meta-analysis. Breast Cancer Res Treat. (2017) 162:201-15. doi: 10.1007/s10549-016-4089-0

59. Cariati M, Bains SK, Grootendorst MR, Suyoi A, Peters AM, Mortimer P, et al. Adjuvant taxanes and the development of breast cancer-related arm lymphoedema. Br J Surg. (2015) 102:1071-8. doi: 10.1002/bjs.9846

60. Invernizzi M, Michelotti A, Noale M, Lopez G, Runza L, Giroda M, et al. Breast cancer systemic treatments and upper limb lymphedema: a risk-assessment platform encompassing tumor-specific pathological features reveals the potential role of trastuzumab. J Clin Med. (2019) 8:E138. doi: $10.3390 / \mathrm{jcm} 8020138$

61. Johnson AR, Granoff MD, Lee BT, Padera TP, Bouta EM, Singhal D. The impact of taxane-based chemotherapy on the lymphatic system. Ann Plast Surg. (2019) 82(4S Suppl 3):S173-8. doi: 10.1097/SAP.0000000000001884

62. Curigliano G, Burstein HJ, Winer EP, Gnant M, Dubsky P, Loibl S, et al. De-escalating and escalating treatments for early-stage breast cancer: the St. Gallen International Expert Consensus Conference on the Primary Therapy of Early Breast Cancer 2017. Ann Oncol. (2017) 28:1700-12. doi: 10.1093/annonc/mdx308

63. Kajiya K, Hirakawa S, Ma B, Drinnenberg I, Detmar M. Hepatocyte growth factor promotes lymphatic vessel formation and function. EMBO J. (2005) 24:2885-95. doi: 10.1038/sj.emboj.7600763

64. Cao R, Björndahl MA, Gallego MI, Chen S, Religa P, Hansen $\mathrm{AJ}$, et al. Hepatocyte growth factor is a lymphangiogenic factor with an indirect mechanism of action. Blood. (2006) 107:3531-6. doi: 10.1182/blood-2005-06-2538

65. Saito Y, Nakagami H, Morishita R, Takami Y, Kikuchi Y, Hayashi H, et al. Transfection of human hepatocyte growth factor gene ameliorates secondary lymphedema via promotion of lymphangiogenesis. Circulation. (2006) 114:1177-84. doi: 10.1161/CIRCULATIONAHA.105.602953

66. Finegold DN, Schacht V, Kimak MA, Lawrence EC, Foeldi E, Karlsson JM, et al. HGF and MET mutations in primary and secondary lymphedema. Lymphat Res Biol. (2008) 6:65-8. doi: 10.1089/lrb.2008.1524

67. Finegold DN, Baty CJ, Knickelbein KZ, Perschke S, Noon SE, Campbell D, et al. Connexin 47 mutations increase risk for secondary lymphedema following breast cancer treatment. Clin Cancer Res. (2012) 18:2382-90. doi: 10.1158/1078-0432.CCR-11-2303

68. Newman B, Lose F, Kedda MA, Francois M, Ferguson K, Janda M, et al. Possible genetic predisposition to lymphedema after breast cancer. Lymphat Res Biol. (2012) 10:2-13. doi: 10.1089/lrb.2011.0024

69. Miaskowski C, Dodd M, Paul SM, West C, Hamolsky D, Abrams G, et al. Lymphatic and angiogenic candidate genes predict the development of secondary lymphedema following breast cancer surgery. PLoS ONE. (2013) 8:e60164. doi: 10.1371/journal.pone.0060164

70. Meens MJ, Sabine A, Petrova TV, Kwak BR. Connexins in lymphatic vessel physiology and disease. FEBS Lett. (2014) 588:1271-7. doi: 10.1016/j.febslet.2014.01.011

71. Smoot B, Kober KM, Paul SM, Levine JD, Abrams G, Mastick J, et al. Potassium channel candidate genes predict the development of secondary lymphedema following breast cancer surgery. Nurs Res. (2017) 66:85-94. doi: 10.1097/NNR.0000000000000203

72. Hadizadeh M, Mohaddes Ardebili SM, Salehi M, Young C, Mokarian F, McClellan J, et al. GJA4/Connexin 37 mutations correlate with secondary lymphedema following surgery in breast cancer patients. Biomedicines. (2018) 6:E23. doi: 10.3390/biomedicines6010023

73. Fu MR, Conley YP, Axelrod D, Guth AA, Yu G, Fletcher J, et al. Precision assessment of heterogeneity of lymphedema phenotype, genotypes and risk prediction. Breast. (2016) 29:231-40. doi: 10.1016/j.breast.2016.06.023

74. Pain SJ, Purushotham AD, Barber RW, Ballinger JR, Solanki CK, Mortimer PS, et al. Variation in lymphatic function may predispose to development of breast cancer-related lymphoedema. Eur J Surg Oncol. (2004) 30:508-14. doi: 10.1016/j.ejso.2004.02.008

75. Cantrell DA. T-cell antigen receptor signal transduction. Immunology. (2002) 105:369-74. doi: 10.1046/j.1365-2567.2002.01391.x

76. Bertozzi CC, Schmaier AA, Mericko P, Hess PR, Zou Z, Chen M, et al. Platelets regulate lymphatic vascular development through CLEC-2-SLP-76 signaling. Blood. (2010) 116:661-70. doi: 10.1182/blood-2010-02-270876 
77. Abtahian F, Guerriero A, Sebzda E, Lu MM, Zhou R, Mocsai A, et al. Regulation of blood and lymphatic vascular separation by signaling proteins SLP-76 and Syk. Science. (2003) 299:247-51. doi: 10.1126/science.1079477

78. Sebzda E, Hibbard C, Sweeney S, Abtahian F, Bezman N, Clemens G, et al. Syk and Slp-76 mutant mice reveal a cell-autonomous hematopoietic cell contribution to vascular development. Dev Cell. (2006) 11:349-61. doi: 10.1016/j.devcel.2006.07.007

79. Herzog Y, Kalcheim C, Kahane N, Reshef R, Neufeld G. Differential expression of neuropilin-1 and neuropilin-2 in arteries and veins. Mech Dev. (2001) 109:115-9

80. Yuan L, Moyon D, Pardanaud L, Bréant C, Karkkainen MJ, Alitalo K, et al. Abnormal lymphatic vessel development in neuropilin 2 mutant mice. Development. (2002) 129:4797-806

81. Coma S, Shimizu A, Klagsbrun M. Hypoxia induces tumor and endothelial cell migration in a semaphorin 3F- and VEGF-dependent manner via transcriptional repression of their common receptor neuropilin 2. Cell Adh Migr. (2011) 5:266-75. doi: 10.4161/cam.5.3.16294

82. Joukov V, Pajusola K, Kaipainen A, Chilov D, Lahtinen I, Kukk E, et al. A novel vascular endothelial growth factor, VEGF-C, is a ligand for the Flt4 (VEGFR-3) and KDR (VEGFR-2) receptor tyrosine kinases. EMBO J. (1996) 15:290-8.

83. Lee J, Gray A, Yuan J, Luoh SM, Avraham H, Wood WI. Vascular endothelial growth factor-related protein: a ligand and specific activator of the tyrosine kinase receptor Flt4. Proc Natl Acad Sci USA. (1996) 93:1988-92.

84. Favier B, Alam A, Barron P, Bonnin J, Laboudie P, Fons P, et al. Neuropilin-2 interacts with VEGFR-2 and VEGFR-3 and promotes human endothelial cell survival and migration. Blood. (2006) 108:1243-50. doi: 10.1182/blood-2005-11-4447

85. van Wetering S, van den Berk N, van Buul JD, Mul FP, Lommerse I, Mous R, et al. VCAM-1-mediated Rac signaling controls endothelial cell-cell contacts and leukocyte transmigration. Am J Physiol Cell Physiol. (2003) 285:C343-52. doi: 10.1152/ajpcell.00048.2003

86. Dominguez GA, Anderson NR, Hammer DA. The direction of migration of T-lymphocytes under flow depends upon which adhesion receptors are engaged. Integr Biol. (2015) 7:345-55. doi: 10.1039/c4ib00201f

87. Kurebayashi S, Ueda E, Sakaue M, Patel DD, Medvedev A, Zhang F, et al. Retinoid-related orphan receptor $\gamma(\operatorname{ROR} \gamma)$ is essential for lymphoid organogenesis and controls apoptosis during thymopoiesis. Proc Natl Acad Sci. (2000) 97:10132-7. doi: 10.1073/pnas.97.18.10132

88. Courtois G, Gilmore TD. Mutations in the NF-kappaB signaling pathway: implications for human disease. Oncogene. (2006) 25:6831-43. doi: 10.1038/sj.onc.1209939

89. Hamidullah, Changkija B, Konwar, R. Role of interleukin-10 in breast cancer. Breast Cancer Res Treat. (2012) 133:11-21. doi: 10.1007/s10549-011-1855-x

90. Lin S, Kim J, Lee MJ, Roche L, Yang NL, Tsao PS, et al. Prospective transcriptomic pathway analysis of human lymphatic vascular insufficiency: identification and validation of a circulating biomarker panel. PLOS ONE. (2012) 7:e52021. doi: 10.1371/journal.pone.0052021

91. Lala PK, Nandi P, Majumder M. Roles of prostaglandins in tumor-associated lymphangiogenesis with special reference to breast cancer. Cancer Metast Rev. (2018) 37:369-84. doi: 10.1007/s10555-018-9734-0

92. Kanady JD, Dellinger MT, Munger SJ, Witte MH, Simon AM. Connexin37 and Connexin43 deficiencies in mice disrupt lymphatic valve development and result in lymphatic disorders including lymphedema and chylothorax. Dev Biol. (2011) 354:253-66. doi: 10.1016/j.ydbio.2011.04.004

93. Sabine A, Agalarov Y, Maby-El Hajjami H, Jaquet M, Hägerling R, Pollmann $\mathrm{C}$, et al. Mechanotransduction, PROX1, and FOXC2 cooperate to control connexin 37 and calcineurin during lymphatic-valve formation. Dev Cell. (2012) 22:430-45. doi: 10.1016/j.devcel.2011.12.020

94. Ferrell RE, Baty CJ, Kimak MA, Karlsson JM, Lawrence EC, Franke-Snyder $\mathrm{M}$, et al. GJC2 missense mutations cause human lymphedema. Am J Hum Genet. (2010) 86:943-8. doi: 10.1016/j.ajhg.2010.04.010

95. Takeda Y, Jothi R, Birault V, Jetten AM. ROR $\gamma$ directly regulates the circadian expression of clock genes and downstream targets in vivo. Nucleic Acids Res. (2012) 40:8519-35. doi: 10.1093/nar/gks630

96. Cadenas C, van de Sandt L, Edlund K, Lohr M, Hellwig B, Marchan $\mathrm{R}$, et al. Loss of circadian clock gene expression is associated with tumor progression in breast cancer. Cell Cycle. (2014) 13:3282-91. doi: $10.4161 / 15384101.2014 .954454$
97. Oh TG, Bailey P, Dray E, Smith AG, Goode J, Eriksson N, et al. PRMT2 and ROR $\gamma$ expression are associated with breast cancer survival outcomes. $\mathrm{Mol}$ Endocrinol. (2014) 28:1166-85. doi: 10.1210/me.2013-1403

98. Oh TG, Wang SM, Acharya BR, Goode JM, Graham JD, Clarke CL, et al. The nuclear receptor, $\operatorname{ROR} \gamma$, regulates pathways necessary for breast cancer metastasis. EBioMedicine. (2016) 6:59-72. doi: 10.1016/j.ebiom.2016.02.028

99. Banerjee D. Connexin's connection in breast cancer growth and progression. Int J Cell Biol. (2016) 2016:11. doi: 10.1155/2016/9025905

100. Sinyuk M, Mulkearns-Hubert EE, Reizes O, Lathia J. Cancer connectors: connexins, gap junctions, and communication. Front Oncol. (2018) 8:646. doi: 10.3389/fonc.2018.00646

101. Aasen T, Leithe E, Graham SV, Kameritsch P, Mayán MD, Mesnil M, et al. Connexins in cancer: bridging the gap to the clinic. Oncogene. (2019) 38:4429-51. doi: 10.1038/s41388-019-0741-6

102. Wu J-I, Wang L-H. Emerging roles of gap junction proteins connexins in cancer metastasis, chemoresistance and clinical application. J Biomed Sci. (2019) 26:8. doi: 10.1186/s12929-019-0497-x

103. Kanczuga-Koda L, Sulkowski S, Lenczewski A, Koda M, Wincewicz A, Baltaziak M, et al. Increased expression of connexins 26 and 43 in lymph node metastases of breast cancer. J Clin Pathol. (2006) 59:429-33. doi: $10.1136 /$ jcp.2005.029272

104. Kanczuga-Koda L, Sulkowska M, Koda M, Rutkowski R, Sulkowski S. Increased expression of gap junction protein-connexin 32 in lymph node metastases of human ductal breast cancer. Folia Histochem Cytobiol. (2007) 45(Suppl 1):S175-80. doi: 10.5603/4481

105. de Sire A, Baricich A, Renò F, Cisari C, Fusco N, Invernizzi M. Myostatin as a potential biomarker to monitor sarcopenia in hip fracture patients undergoing a multidisciplinary rehabilitation and nutritional treatment: a preliminary study. Aging Clin Exp Res. (2019). doi: 10.1007/s40520-019-01436-8

106. Dennis KL, Blatner NR, Gounari F, Khazaie K. Current status of interleukin10 and regulatory T-cells in cancer. Curr Opin Oncol. (2013) 25:637-45. doi: $10.1097 / \mathrm{cco} .0000000000000006$

107. Knechtel G, Hofmann G, Gerger A, Renner W, Langsenlehner T, Szkandera J, et al. Analysis of common germline polymorphisms as prognostic factors in patients with lymph node-positive breast cancer. J Cancer Res Clin Oncol. (2010) 136:1813-9. doi: 10.1007/s00432-0100839-2

108. Kaewkangsadan V, Verma C, Eremin JM, Cowley G, Ilyas M, Eremin O. Tumour-draining axillary lymph nodes in patients with large and locally advanced breast cancers undergoing neoadjuvant chemotherapy (NAC): the crucial contribution of immune cells (effector, regulatory) and cytokines (Th1, Th2) to immune-mediated tumour cell death induced by NAC. BMC Cancer. (2018) 18:123. doi: 10.1186/s12885-0184044-z

109. Mohamed HT, El-Husseiny N, El-Ghonaimy EA, Ibrahim SA, Bazzi ZA, Cavallo-Medved D, et al. IL-10 correlates with the expression of carboxypeptidase B2 and lymphovascular invasion in inflammatory breast cancer: the potential role of tumor infiltrated macrophages. Curr Probl Cancer. (2018) 42:215-30. doi: 10.1016/j.currproblcancer.2018. 01.009

110. Miller K, Christmon D, Perkins S, Sun J, Schneider B, Storniolo A, et al. A pilot study of vascular endothelial growth factor inhibition with bevacizumab in patients with lymphedema following breast cancer treatment. J Clin Oncol. (2009) 27(15_suppl):9523. doi: 10.1200/jco.2009.27.15_suppl. 9523

Conflict of Interest: The authors declare that the research was conducted in the absence of any commercial or financial relationships that could be construed as a potential conflict of interest.

Copyright (c) 2020 Invernizzi, Lopez, Michelotti, Venetis, Sajjadi, De Mattos-Arruda, Ghidini, Runza, de Sire, Boldorini and Fusco. This is an open-access article distributed under the terms of the Creative Commons Attribution License (CC BY). The use, distribution or reproduction in other forums is permitted, provided the original author(s) and the copyright owner(s) are credited and that the original publication in this journal is cited, in accordance with accepted academic practice. No use, distribution or reproduction is permitted which does not comply with these terms. 